\title{
A Comparison of Blood Viscosity between the Adult Sheep and Newborn Lamb. The Role of Plasma and Red Blood Cell Type
}

\author{
LISE RIOPEL, JEAN-CLAUDE FOURON, ${ }^{(16)}$ AND HARRY BARD \\ Cardiology and Neonatology Sections, Departments of Pediatrics and Pediatric Research, Sainte-Justine Hospital and \\ University of Montreal, Montreal and Quebec, Canada
}

\begin{abstract}
Summary
Adult sheep and newborn lamb blood viscosity ( $\mathrm{Vc}$ ) have been compared by taking into account not only the hematocrit, but also the type of the red cells (adult or fetal) in the circulation and the plasma Vc. At all shear rates studied the whole blood Vc of the adult was higher than that of the newborn. Plasma Vc was 1.58 \pm 0.18 centipoises in the adult compared to $1.21 \pm 0.19$ in the newborn group $(P<0.001)$. The mean relative apparent viscosity (whole blood Vc/plasma Vc) was higher in the newborn although the difference was not significant.
\end{abstract}

\section{Abbreviations}

CP, centipoise

Ht, hematocrit

Vc, viscosity

In a recent study, blood viscosity of adults and human newborns was compared to determine the part played by the presence of fetal red cell and the plasma viscosity. This work showed that for the same hematocrit adult blood had a higher viscosity than that of the newborn. This was due to a higher viscosity of adult plasma (10).

Because the newborn lamb is frequently used as an experimental model for fetal and neonatal circulatory (5) as well as metabolic studies (8) and the results are extrapolated to humans, it was considered of utmost importance to obtain data on rheologic properties of adult and newborn blood in this species.

\section{MATERIALS AND METHODS}

Viscosity studies were carried out on blood samples taken from adult sheep and newborn lambs younger than $48 \mathrm{~h}$ of age. Bard et al. (1) have shown that at this early age the blood contains over $75 \%$ of fetal hemoglobins. In both instances venous blood was collected into plastic syringes that had been flushed with sodium heparin. A total of 28 adult and 32 newborn samples were collected. They were centrifuged $(4000 \times g$ for $10 \mathrm{~min})$ and the cells resuspended in plasma in order to obtain hematocrit levels varying from $30-71 \%$. Manipulations and measurements were completed within $2 \mathrm{~h}$ of sampling. The variations in the number of data points are due to the fact that on a few samples there was some blood loss during the manipulations, thus viscosity could not be obtained at all of the shear rates.

Vc was measured with a Wells-Brookfield cone-plate viscometer (model LVTcp). The shear stress of the samples was determined at shear rates of $11.5,23,46,115$, and $230 \mathrm{sec}^{-1}$. Vc was calculated as described by Wells et al. (13) and Rand et al. (9). The whole blood $\mathrm{Vc}$ was first measured in relation to blood $\mathrm{Ht}$ at the shear rates previously mentioned. The rate of change of $\mathrm{Vc}$ of adult and newborn blood in presence of change in $\mathrm{Ht}$ was studied by plotting the logarithm of $\mathrm{Vc}$ against Ht. The statistical analysis of the regression lines were performed according to the methods outlined in Snedecor and Cochran (11). A preliminary test of the residual variances about the regression lines was done when these tests were not significant, it was then possible to assess the equality of the two slopes. If these tests were not significant the common values of the slopes were estimated, and the intercepts were calculated. The equality of the two intercepts could then be assessed. The Vc of adult and newborn blood in relation to the shear rate was also compared at three Ht ranges: $30-40,50-60$, and $60-70 \%$ ). The $\mathrm{Vc}$ found for each sample was divided by the $\mathrm{Vc}$ of its plasma to obtain the relative apparent $\mathrm{Vc}(2)$. This ratio reflects the rheologic properties of the erythrocyte suspension. Unpaired Student's $t$ test was used for statistical analyses unless specified otherwise.

\section{RESULTS}

The influence of $\mathrm{Ht}$ changes on the apparent $\mathrm{Vc}$ of neonatal and adult blood at four different shear rates is shown in Figure 1. In all instances $\mathrm{Vc}$ increases with a rise of $\mathrm{Ht}$, and at a given $\mathrm{Ht}$ the $\mathrm{Vc}$ decreases with increasing shear rates. Absolute values of adult blood appear to be higher than those of the newborn lamb. The comparison of the rate of change of the $\mathrm{Vc}$ of adult and newborn blood in presence of change in $\mathrm{Ht}$ is shown in Figure 2. The tests for the equality of variances were not significant at the 0.05 level. The tests of the equality of the slopes were also not significant at 0.05 level. All the tests of the equality of the intercepts were highly significant $(P<0.001)$ for all shear rates studied. Figure $3 \mathrm{~A}, \mathrm{~B}$, and $\mathrm{C}$ show the quantitative comparison between the two types of blood at three different ranges of $\mathrm{Ht}$. The apparent $\mathrm{Vc}$ of adult blood is consistently greater than that of the newborn. This difference is significant $(P<0.01)$ at $\mathrm{Hts}$ ranging from $50-60 \%$ irrespective of the shear rate studied. At the $\mathrm{Ht}$ range of 30-40\% the difference was significant $(P<0.01)$ only at shear rate of 115 and $230 \mathrm{sec}^{-1}$.

Plasma Vc averaged for the newborn $1.21 \pm 0.19 \mathrm{cp}$ and for the adult $1.58 \pm 0.18 \mathrm{cp}$. The difference was significant $(P<0.001)$. Relative apparent Vc (whole blood Vc divided by the plasma Vc) was plotted against the shear rate for the same three Ht ranges as shown in Figure 3 (Figure 4). In all instances and for all shear rates, the relative $\mathrm{Vc}$ of the adult blood was lower than that of the newborn blood, although the differences were not statistically significant.

\section{DISCUSSION}

This study demonstrates that at a given $\mathrm{Ht}$, whole blood $\mathrm{Vc}$ of adult sheep is significantly higher than that of the newborn lamb. As observed with human blood, the difference between adult and newborn blood Vc is due to the plasma Vc, which is more elevated 

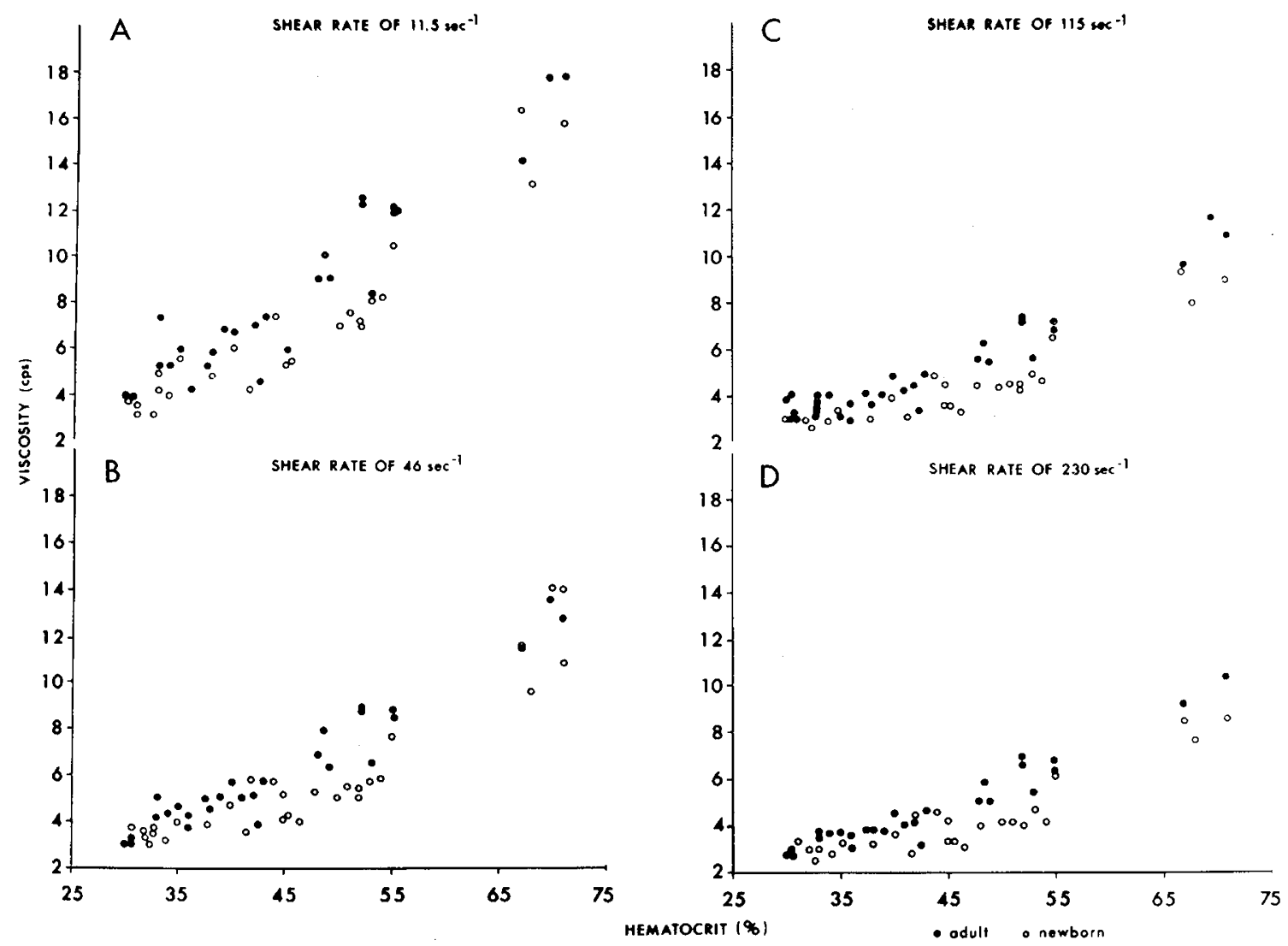

Fig. 1. Comparing the relationship of hematocrit changes on whole blood viscosity of adult and newborn blood at different shear rates: $(A)$ 11.5; (B) 46; (C) 115; and (D) $230 \mathrm{sec}^{-1}$.
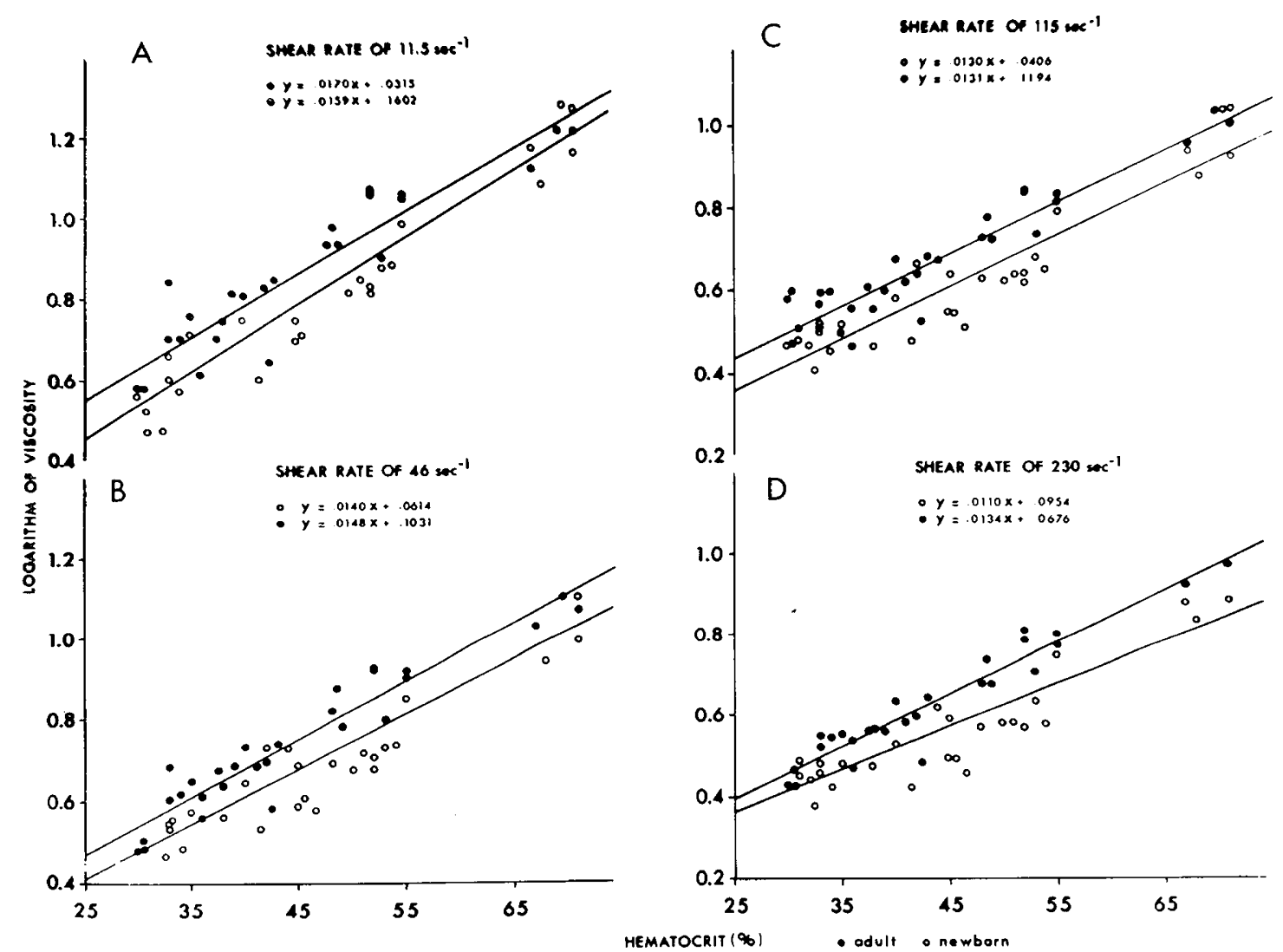

Fig. 2. Influence of hematocrit changes on whole blood viscosity expressed in logarithm values at different shear rates of $(A) 11.5 ;(B) 46 ;(C) 115$; and $(D) 230 \mathrm{sec}^{-1}$ 
in the adult blood (10). Plasma Vc is primarily related to the fibrinogen concentration (14). Kisker et al. (6) have shown that in the newborn lamb, fibrinogen concentration at birth averages 117 $\mathrm{mg} / \mathrm{dl}$, which is $60 \%$ of the adult sheep level. Although the direct effect of fibrinogen has not been demonstrated in the present study, it can be speculated that the lower plasma Vc of the newborn lambs may be due, at least in part, to the lower fibrinogen concentration. Chien et al. (4) have also shown that fibrinogen affects whole blood Vc at low shear rates by inducing red cells aggregation.

Several comparative hemorheologic studies have revealed that various mammalian species have erythrocytes with different properties $(3,12)$. For example, at low shear rates, in the presence of plasma proteins (fibrinogen, macroglobulins) adult sheep erythrocytes do not form large aggregates like those observed in the human. Also, adult sheep erythrocytes were found to be more rigid than the adult human cells. Furthermore, deformability could be different according to the type (adult or fetal) of the red

WHOLE BLOOD VISCOSIIY
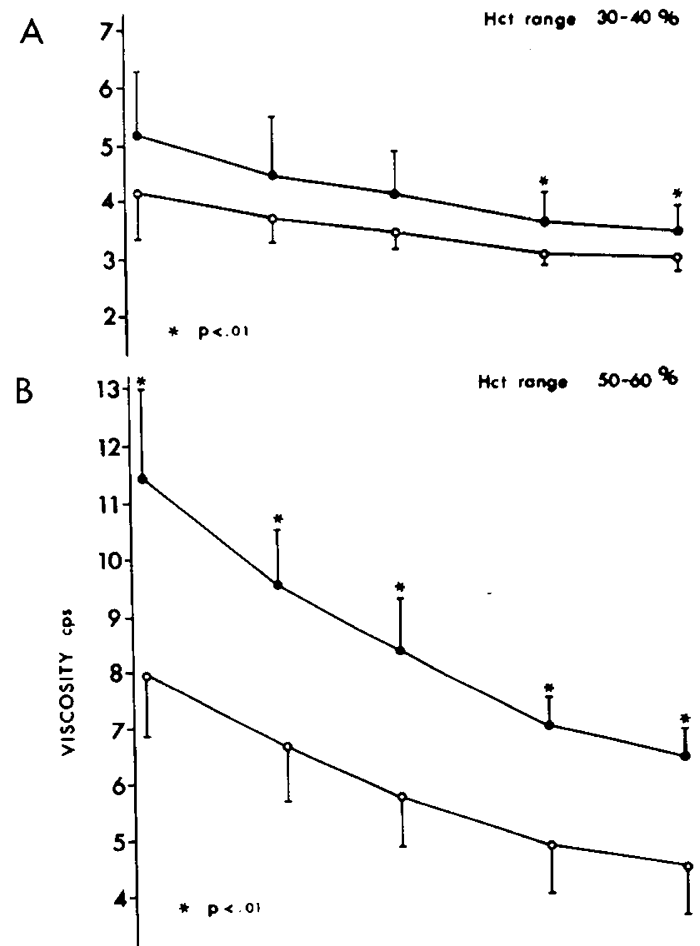

C

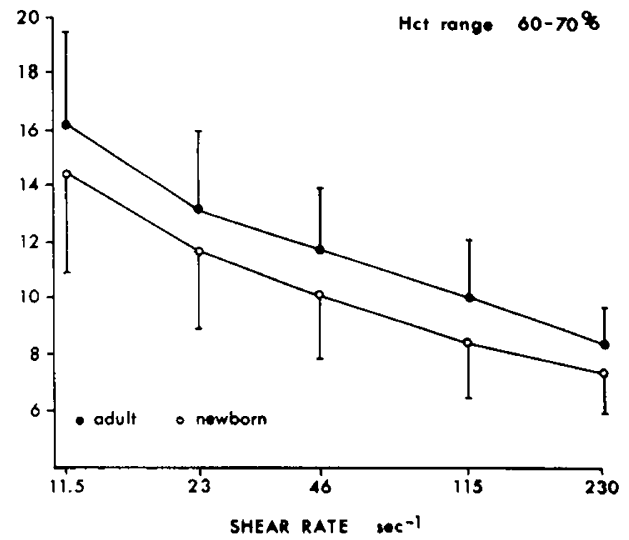

Fig. 3. A comparison of fetal and adult blood based on the relationship between whole blood viscosity and shear rates at three different ranges of hematocrit: $(A) 30-40 \% ;(B) 50-60 \%$; and $(C)$ 60-70\%. The lines join the mean and a S.D. The $\mathrm{N}$ values (number of viscosity studies) for $(A)$ adult, 12 and newborn $11 ;(B)$ adult, 5 and newborn, 7 ; and $(C)$ adult, 12 and newborn, 16.
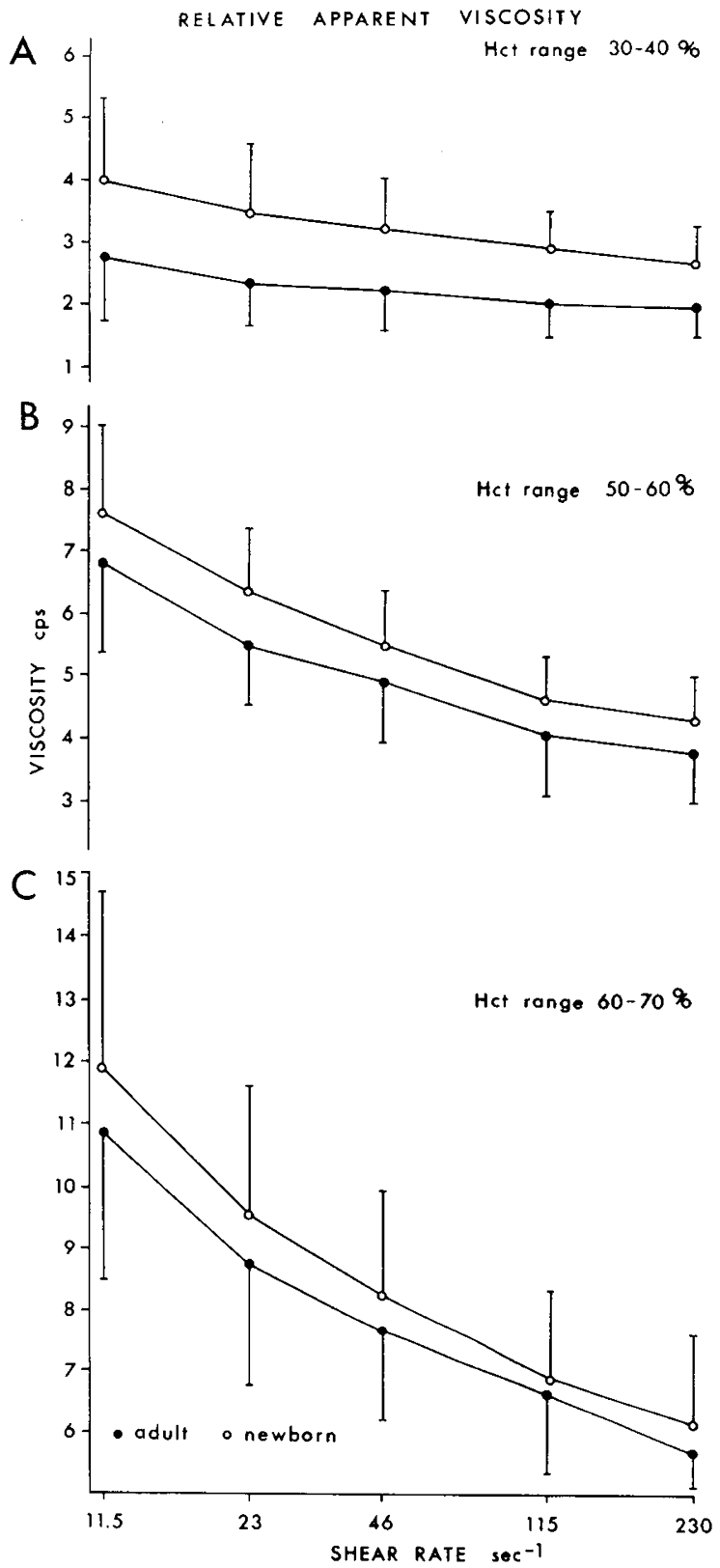

Fig. 4. A comparison of fetal and adult blood based on the relationship between relative viscosity and shear rates at three different hematocrit ranges $(A)$ 30-40\%; $(B) 50-60 \%$; and $(C)$ 60-70\%. Relative viscosity is the ratio of whole blood and plasma viscosity. The lines join the mean and a S.D. N values for $(A)$ adult, 5 and newborn, $5 ;(B)$ adult, 5 and newborn, 9; and $(C)$ adult, 7 and newborn, 13.

cells in the same species. This is seen in the human being where fetal red cells are less deformable than adult red cells and thus contribute to the increase in Vc at higher shear rates $(7,10)$. In spite of these differences, it is of interest to report that the absolute values of whole blood $\mathrm{Vc}$ found in the present study are similar to that found in human blood (10).

All these different factors should always be taken into account when applying Vc studies on ovine blood to human being, especially during the perinatal period.

\section{REFERENCES AND NOTES}

1. Bard, H., Fouron, J. C., Grothe, A. M., Soukini, M. A., and Cornet, A.: The adaptation of the fetal red cells of newborn lambs to extrauterine life: the role of 2,3 DPG. Pediatr. Res., 10: 823 (1976).

2. Chien, S.: Shear dependence of effective cell volume as a determinant of blood viscosity. Science, 168: 977 (1970).

3. Chien, S., Usami, S., Dellenback, R. J., and Bryant, C. A.: Comparative hemo- 
rheology-Hematological implications of species differences in blood viscosity. Biorheology, 8: 35 (1971).

4. Chien, S., Usami, S., Dellenback, R. J., and Gregersen, M. I.: Shear dependent interaction of plasma proteins with erythrocytes in blood rheology. Am. J. Physiol., 219: 143 (1970).

5. Fouron, J. C. and Hebert, F.: The circulatory effects of hematocrit variations in normovolemic newborn lambs. J. Pediatr., 82: 996 (1973).

6. Kisker, C. T., Robillard, J. E., and Clarke, W. R.: Development of blood coagulation-A fetal lamb model. Pediatr. Res., 15: 1045 (1981).

7. Gross, G. P. and Hathaway, W. E.: Fetal erythrocyte deformability. Pediatr. Res., 6: 593 (1972).

8. Leake, R. D., Chan, G. M., Zakauddin, S., Dodge, M. E., Fisher, R. H., Bier, D. M., and Oh, W.: Glucose perturbation in experimental hyperviscosity. Pediatr. Res., 14: 1320 (1980).

9. Rand, P. W., Lacombe, E., Hung, H. E., and Austin, W. H.: Viscosity of normal human blood under normothermic and hypothermic conditions. J. App. Physiol., 19: 117 (1964).

10. Riopel, L., Fouron, J. C., and Bard, H.: Blood viscosity during the neonatal period. The role of plasma and red blood cell type. J. Pediatr., 100: 449 (1982).

11. Snedecor, G. W. and Cochran, W. C.: Statistical methods. In: Sixth Edition, Ames Iowa. pp. 432-6 (Iowa State University Press, 1976)

12. Usami, S., Chien, S., and Gregersen, M. I.: Viscometric characteristics of blood of the elephant, man, dog, sheep and goat. Am. J. Physiol., 217: 884 (1969).

13. Wells, R. E., Denton, R., and Merrill, D. W.: Measurement of viscosity of biologic fluids by cone-plate viscometer. J. Lab. Clin. Med., 57: 646 (1961).

14. Wells, R. Jr., Gawronski, T. H., Cox, P. J., and Perera, R. D.: Influence of fibrinogen on flow properties of erythrocytes suspensions. Am. J. Physiol., 207: 1035 (1964).

15. The authors gratefully acknowledge the valuable assistance of Micheline Raymond in the preparation of this manuscript.

16. Requests for reprints should be addressed to: Jean-Claude Fouron, Sainte-Justine Hospital, 3175 Sainte-Catherine Road, Montreal, (Quebec), Canada, H3T 1C5.

17. Work supported in part by the Canadian Heart Foundations and the Medical Research Council of Canada.

18. Received for publication April 22, 1982.

19. Accepted for publication October $4,1982$. 